\title{
Syntactic Forms and Their Sequential Features in Advice-Giving in Mandarin Conversation
}

\author{
Yongfang Yang1,2 \\ ${ }^{1}$ School of Foreign Languages, Shanxi University, Taiyuan, China \\ ${ }^{2}$ School of Foreign Languages, Business College of Shanxi University, Taiyuan, China \\ Email:1834930997@qq.com
}

How to cite this paper: Yang, Y. F. (2020). Syntactic Forms and Their Sequential Features in Advice-Giving in Mandarin Conversation. Open Journal of Modern Linguistics, 10, 277-307.

https://doi.org/10.4236/ojml.2020.104016

Received: June 25, 2020

Accepted: August 4, 2020

Published: August 7, 2020

Copyright ( 2020 by author(s) and Scientific Research Publishing Inc. This work is licensed under the Creative Commons Attribution International License (CC BY 4.0).

http://creativecommons.org/licenses/by/4.0/ (c) (i) Open Access

\begin{abstract}
Advice-giving in Mandarin conversation is conducted through various syntactic forms. In this article, we explore several syntactic forms the speakers usually employ when doing advice-giving. An initial examination showed a difference in the distribution of advice-giving made through these practices. They are sequentially-specific syntactic forms of advice-giving and they are sensitive to the sequential environment. Further exploration on this distributional pattern suggested that the advice forms speakers selected display their evaluation of the sequential environment or interactional situation and it is closely related to the speaker's orientation to deontic rights to give advice on a particular sequential position.
\end{abstract}

\section{Keywords}

Advice-Giving, Conversation Analysis, Practices, Deontic Right

\section{Introduction}

Advice-giving is a frequently occurred speech act in our daily life. People tend to help others who are in a difficulty or in a problematic situation by offering any kind of service or giving advice to get them out of the problematic situation. There are also cases when no problem is displayed, people still give advice to others in order to better their condition or situation. Since the core of the social science is "the exploration into and explanation of how social order and cohesion is maintained and how cooperation, collaboration and altruism are possible, given the pursuit of individuals' self-interests" (Kendrick \& Drew, 2016), advice-giving is one of the critical altruistic social actions to be studied in the social 
science.

In this paper we will term the one who gives advice as adviser or advice giver and the one who was given the advice as advisee or advice recipient. One of the key features to ascribe an action as advice-giving is that the advisee is beneficiary of the suggested action (Couper-Kuhlen, 2014), and the distinction between offer and advice-giving is the agent of the suggested action. It is also this benefactive nature of advice-giving that makes altruism a possible theory to account for the production of the action per se in sociology and social psychology. Sacks once indicated in his lectures that "the knowledge of the trouble is often sufficient to bring one into causal involvement" (Sacks, 1995). As for advice-giving, other-attentive action, people have a natural tendency to show their consideration and helpfulness to others in social interaction. This social relation is characterized by altruism (Warneken \& Tomasello, 2009).

In the field of linguistic studies, advice is explored within two influential theories, speech act theory and politeness theory. In speech act theory, advice is one kind of speech acts within the category of "directives" (Searle, 1979) and distinguished from another kind of speech acts request in the benefactive status, because it is delivered to benefit the recipient (Searle, 1969; Martinez-Flo, 2005). According to Brown and Levinson's politeness theory, advice is regarded as an FTA (face threatening act), threatening the recipient negative face. In their illustration, the advice prefaced with "I think perhaps..." is one of the strategies for managing FTA (Brown \& Levinson, 1987).

In the field of interactional research, conversation analytic studies of advice-giving have been conducted in the institutional talk, such as healthcare settings (Heritage \& Sefi, 1992; Heritage \& Lindström, 1998, 2012; Kinnell \& Maynard, 1996; Jefferson \& Lee, 1992); helpline (Butler et al., 2009; Butler et al., 2010; Emmison \& Firth, 2012); educational settings (Waring, 2007, 2012; Vehviläinen, 2009, 2012) etc. as well as in the mundane conversation (Shaw, 2013; Shaw, Potter, \& Hepburn, 2015). Among these studies, the fundamental research is Heritage \& Sefi's study (1992) on the advice between health visitor and first time mother, in which advice is described as something "describes, recommends or otherwise forwards a preferred course of future action". They also put forward two crucial dimensions in advice "normativity" and "asymmetry". The former refers to nature of the suggested action, and the latter refers to the asymmetry in knowledge between the two speakers (Heritage \& Sefi, 1992).

From conversation analytic perspective, some studies are worked on the syntactic designs of the social action and explore their regularities in the interaction. For example, Wotton (1981) examined syntactic form declarative $I$ want and interrogative can $I$ to do the request by the children aged four in a sequential environment after an initial request has been turned down and after the use of imperatives by parents which showed the different syntactic constraints positioned on the following turn by the recipient. Lindström (2005) explored the request made by senior citizens through imperative, questions and statements and con- 
cluded that the choice of syntactic form unfolded their orientation to entitlement to the requested task within the caregiving institutional context. Curl (2006) examined the sequential features of different syntactic format of offer. Conditional if is always used for the reason-for-calling offer, do you want me to $X$ is used for offer for problems educed from prior talk, and it is never used for the offer responsive overt problem. Curl and Drew (2008) compared two forms of requesting can you... with $I$ wonder if... in different sequential environment and showed that the different request forms displayed the entitlement and acknowledged contingency (Drew, 2013). As far as apology concerned, apology formulations are proportional to the offenses they address (Heritage \& Raymond, 2016; Heritage, Raymond, \& Drew 2019). In terms of invitation, three kinds of syntactic forms have a distributional pattern closely related to the anticipation of the likelihood of the success of an invitation in Mandarin mundane conversation (Yu \& Wu, 2018).

Randall (1995) pointed out that as for unsolicited advice, how the form of advice relates to the sequential environment needs to be explored. Shaw (2013) explicates the form of advice in terms of entitlement and contingency in the daughter-mother telephone conversation. He concludes the constraining forms of advice are put forward with a local warrant and the less constraining forms of advice are given taking local contingencies into consideration. Nevertheless, the constraining forms in his paper refer to the syntactic forms which furnished recipient with little optionality in doing the suggested action, including imperatives, verbs with obligation, tags questions etc. and the less constraining forms of advice refers to those syntactic forms which provide the recipient with more contingency, including "just description", or something which is defeasible other than advice. Leppanen (1998) studied the advice-giving between Swedish district nurses and patients and found nurses employed imperatives and modal verbs of obligation in the sequential locations in which patients seems to understand there is a problem but do not have any solutions, by contrast, nurses employed presentations of proposed action and descriptions of patient's future actions, the mitigated forms, in the sequential locations in which patients do not even seem to understand there is a problem.

This paper is going to explore two kinds of syntactic forms of explicit advice in Mandarin conversation which belong to constraining forms of advice according to Shaw, that is, the syntactic form has constraint on the recipient to do the suggested action (Shaw, 2013). We examine the sequential environment of these two kinds of syntactic forms employed in delivering advice in Mandarin mundane conversation and found they are non-equivalent forms in a particular interactional situation, and this distributional pattern is sensitive to their sequential environment. At the end of the paper we also offer an account for this pattern on deontics. Speakers have an orientation to the recognition, evaluation and understanding of their deontic rights in s specific sequential environment to give advice. 


\section{Data and Methodology}

The data we collected are all naturally occurring mundane conversation conducted between family members, peers, friends, classmates and couples etc with almost equal social status. The participants in the following conversations are all anonymous. All the data are transcribed in accordance with Gail Jefferson's transcription system (Atkinson \& Heritage, 1984).

The methodology this paper adopted is conversation analysis, which is a systematical study of the talk-in-interaction and is designed to discover the natural living order of social activities (Mondada, 2013), through examining language resources and other nonverbal resources. CA (conversation analysis), a science of social action (Drew, 2005), mainly unveils the regularities in social action and interaction such as the patterns, practices in terms of the basic elements in CA like TCU (turn construction unit), FPP (first pair part), SPP (second pair part), adjacency pair, turn-taking, turn design, social action and sequence organization etc. Drew pointed that in recent years a new direction in the CA study is "exploring the systematic basis for selection of one form from among alternative constructions or formats for doing certain action" (Drew, 2013).

Before the analysis, we delimit the boundaries of our study and our data in terms of the following aspects: 1) We confine our study only in mundane conversations for that the institutional talk always has distinctive features other than the mundane conversation (Heritage, 2005). 2) As far as advice-giving concerned, there is a distinction between the unsolicited advice and the solicited advice, only the former the unsolicited interaction-generated advice is the focus of our study, for that as for the solicited advice, the advice seeker is oriented to put the advice-giver in a $\mathrm{K}+$ position before the advice is sought. However, it may not be the truth in the unsolicited advice in which there is a back-and-forth negotiation in the epistemic authority, deontic rights etc, which are dynamically constructed in the interaction between the two speakers. 3) There is also a dichotomy in advice, "prohibitive" advice and "instructive" advice. We only focus on the instructive advice which forward a future action rather than to prevent or stop an action. More related examples are needed to testify whether the prohibitive advice-giving presents the identical sequential features as the instructive advice-giving, and it is not the task included in this study. 4) All the data in this study are explicit advice rather than implicit advice or advice camouflaged in other action, such as assessment, my side telling etc. 5) The advice analyzed in the paper are all the first time advice in the sequence, we excludes the advice in pursuit or when the advice at their second or third appearance. In a word, the object in this study is the explicit unsolicited instructive advice delivered in the following practices for the first time in a sequence in Mandarin mundane conversation.

The procedures to conduct a conversational analysis are as follows: 1) build a collection of target phenomenon, 2) do the detailed analysis of the phenomena, including its turn design and the sequential position, in the meantime if there 
are deviant cases, analyze in order to testify the regularities or the normativity displayed in the non-deviant cases, 3) present the discovered regularity and produce a formal account of this phenomenon.

Based on this methodology, this paper is deployed into five parts. The first part is the introduction of the research including the literature review on this field. The second part is the introduction of the data and methodology adopted in the research. The third part is the presentation of the main analysis of the data and the features of their sequential environment. The fourth part is the discussion to find out the account of the phenomena on the basis of the analysis of the data, and at the same time the deviant cases are provided to verify the regularities. That is to say, if the regularity is broken and the imperative is advice, then the imperatives are always accompanied by an account, or else the imperative is not advice at all. The last part is the conclusion of the paper including the practical significance of the study and the direction of the study.

\section{Analysis}

We observe the most typical advice-giving syntactical forms in our collected data and analyze their sequential features which demonstrate that people have an orientation to dispose different syntactical forms attentively and sensitively to its local sequential environment. Advice is frequently given when the advisee has a problem or even no problem, but whether the advisee's situation, problematic or not, needs a piece of advice depends on the adviser's evaluation and judgement based on the adviser's epistemic status. We divide the sequential environment under which advice is given in a gradient: the explicit problem with no solution is at one end and no problem displayed and identified is at the other end. In the following analysis, the sequential environment of two kinds of syntactic forms advice takes on following features: 1) Two types of imperative typed advice do $X$, you do $X$ appear under the sequential environment of explicit problem without any possible solution 2) Three declarative typed advice you can..., I think..., I tell you... appear under the sequential environment of no problem and downgraded explicit problem.

\subsection{Sequential Environment of Imperative Typed Advice $D o X$, You Do X}

Imperatives are frequently used in advice-giving. Given the nature of the action of advice per se, the agent of the suggested action is the advisee; an overwhelming majority of imperatives of this kind are directives. In our data advice given through imperative forms exhibits some commonalities in their sequential environment. The most typical imperatives to do the advice-giving in Mandarin are You do $X$ and Do $X$. These two formats are employed when the explicit problem is displayed by the advisee and recognized by the adviser or when an explicit problem identified by the adviser and in both cases no solution has come up yet. In some examples evidences are found in the lexical choice to indicate that the 
problems are of great severity or urgency.

\subsubsection{Explicit Problem Displayed by the Advisee and Recognized by the Adviser}

The first kind of sequential environment is that the problems are displayed by the advisee explicitly and overtly in the turn preceding the advice, and the adviser also recognizes the problem and gives advice in imperatives. The advice in imperatives appears alone after the problem.

\section{Example 1}

14 CLA: 回 的 时候, 然后: 再: (.) 到 这坐吧, 到这儿坐上座 就行。

Hui de shihou, ranhou:zai: (.) dao zhe zuo ba, dao zhe'er zuo shang zuo jiu xing.

Back NOM time, then again to here take PRT, to here sit up seat just Ok.

When back, then again then again take (bus) here, just take a seat here.

15 HEB:

16

我回来的时候 感觉 找 不见。

Wo huilai de shihou ganjue zhaobujian

I back NOM time feel find $\mathrm{N}$ out.

When I am going back (I) feel I can't find it.

17 CLA: 你问一下人 么。

$\mathrm{Ni}$ wen yi xia ren me.

You ask NUM C someone PRT.

You ask someone.

18 HEB：你看，坐 103

Nikan, zuo 103

的 话, 坐 103 我 不走这。

You look, take NO.103 NOM if, take 103 IN go this.

Look, if take NO.103 bus, I do not go this way.
我怕我找不见(.)

Wo pa wo zhao bu jian

I afraid I find $\mathrm{N}$ out

I am afraid that I can't find it

In this example Clare answered Hebe's inquiry on how to take a bus to a restaurant mentioned in the previous talk and by the way Clare added to inform Hebe where to take a bus to go back at line 14. The occasioned topic was topicalized by Hebe in the following turn. Hebe showed her worry in finding the way back in the subsequent turn I am afraid... in the overlapping part and then after overlapping she reformulated it into when I am going back I feel..., which turns a worry in mind and in imagination into a more certain feeling, turns a potential problem into an explicit problem, intensifying the uncertainty in finding the way back.

Under this sequential environment constructed at line $15-16$, an explicit 
problem is displayed by the advisee. Clare recognized the problem and gave a possible solution through an imperative on the phone before Hebe prepared to go back. Besides, no other possible solutions appeared yet before this imperative advice at line 17 as a kind of alleviation to the problem.

Sometimes when the problem is displayed by the advisee and the adviser also evaluates the problematic situation with the negative assessment or the affect-laden interjection such as "aiya" in Mandarin which projects something bad in the following turn.

\section{Example 2 \\ 29 \\ 然后正准备 进去呢, \\ ranhou zheng zhunbei Jinqu ne, \\ then DUR prepare enter PRT, \\ then (I am) preparing entering,}

28 MAY: 我 正在 “进那个:” 㕪刚才才注册的一个东西, 注册了一个。

Wo zhengzai jin nage e gangcai cai zhuce de yi ge dongxi. Zhuce le yige.

I DUR enter that $\mathrm{C}$ e just now just register NOM NUM C thing. Register PFV NUM C.

I am going to enter a thing registered just now. Register a thing.

30 TOM: 哇,

Wa,

31 MAY: 找 不到: 我:

Zhao bu dao wo

Find $\mathrm{N}$ out I

I can not find it

32 TOM: 好 麻烦

㖏: 那你 直接 在 淘-

Hao mafan nie na ni zhijie zai tao

Good troublesome PRT then you directly at Tao (unfinished a Name of Online retailers)

So troublesome, then you directly at Tao

33 MAY:

是啊, 挺麻烦的。

Shi a, ting mafan de.

Yes PRT, very troublesome NOM.

Yes, so troublesome.

34 TOM: 你把 那 个书包 名字记下来 在 淘宝上搜 一 搜 呗。

Ni ba na ge shubao mingzi jixialai zai Taobao shang sou yi sou bei.

You BA that $\mathrm{C}$ schoolbag name note down DUR Taobao up search NUM search PRT.

(You) note down the name of that schoolbag and search it at Taobao.

35 MAY: 就在京东 啊: 我搜搜 不出来: 我 把那个旗舰店 搜了也搜不出来,

Jiu zai jingdong a, wo sou sou bu chulai, wo ba na ge qijiandian sou le ye sou bu chulai,

Just at Jingdong a, I search search N out, I BA that C Flagship store search PRF also search N out.

Just at Jingdong, I can’t search it out, I searched that flagship and cannot find it.

Jingdong (name of online retailer) 
In this telephone conversation, May described the process she was searching online the discounted product she wanted to buy, and reported the problem she met on the spot. After the overlapping at line 30-31, May abandoned her turn, and Tom resumed his turn. The report of problematic situation occasioned the evaluation of the process as "troublesome" at line 32 from Tom, which demonstrates the Tom's interpretation of her turn at line 28 - 29, 31 as a real problem, and the second TCU of the turn at line 32 began to offer a possible solution in order to help May out of the trouble. The advice was put forward in an imperative form to direct the other party to do something directly. The sequential environment for the advice is urgent, because the girl was searching online at the moment and the discounted product online has a time limit. The intersubjectivity is achieved through displaying an explicit problem by the advisee and recognizing the trouble by the adviser, which is the prerequisite and also the particular local sequential environment for the advice at line 32 and 34 . In the both cases the imperatives alone constitute a turn in the conversation.

\subsubsection{Explicit Problem Identified by the Adviser}

Sometimes the problem is not demonstrated explicitly by the advisee by words; however the problem is noticed, perceived, identified and evaluated by the adviser as an overt problematic situation demanding advice.

\section{Example 3}

43 KAT: $\mathrm{Mm} \mathrm{Mm}$ 学姐, 你 是不是 感:冒了, 嗓子 听见有点 [亚。 Mm Mm xuejie, ni shibushi gaomao le, sangzi tingjian youdian ya. Mm Mm school elder sister, you BE N BE catch a cold, throat sound a little hoarse Mm Mm school sister, did you catch a cold, the voice sounds a little hoarse.

44 JEN:

45

$$
\begin{array}{ll}
\text { 我嗓子 有点 } & \text { 那个(.)最近 有点 那个 hhenhh } \\
\text { Wo sangzi youdian na ge zuijin youdian na ge hhenhh } \\
\text { I throat a little that } \mathrm{C} \text { recently a little that } \mathrm{C} \text { hhenhh }
\end{array}
$$

My throat is a little that, recently a little that hhenhh

46

KAT: \$多喝点 水, 吃喝点那个 (下)火 的。

Duo he dian shui, chi-he dian na ge xiahuo de.

More drink $\mathrm{C}$ water, eat drink $\mathrm{C}$ that $\mathrm{C}$ down fire NOM.

Drink more water, eat drink something to down the fire.

47 JEN: 恩, 没事儿。

En, meishier

H'm it doesn't matter.

H'm, it doesn't matter. [ang ang:

Ang ang

H'mH'm

H'mH'm 
In this example, Kate inquired Jenny about the examination in the prior turns and Jenny answered without any cough. Kate began a new turn with a turn-initial delay and an address term which prefaced a shift in the topic at line 43. This turn changed the topic to an inquiry into Jenny's health condition. The yes/no question at line 43 come up to seek confirmation accompanied with evidentials because Kate perceived Jenny's problem on the throat through Jenny's hoarse voice during the call. After Jenny confirmed her problematic condition, the advice at line 46 is delivered instantly in an imperative format before any other possible solution mentioned. The intersubjectivity on an explicit problem is achieved by both parties before the advice is given.

Examples of this kind also justified that the advice giver has an orientation to formulate the advice in these two imperative forms in accordance with the evaluation on the explicitness and sometimes even severity of the problem in the specific interaction situation. Besides, what need to be noticed is that imperatives appear alone under this kind of sequential environment.

\subsection{Sequential Environment of Declarative Typed Advice I Think..., I Tell You ..., You Can...}

In this part the interactional situation discussed refers to the following two kinds of sequential environment of advice: downgraded explicit problem and no problem. In this sequential environment three syntactic formats frequently are employed to do the advice-giving: I think that you..., I tell you that... and You can.... In our collected data, these three practices are often employed in the sequential environment which is not in parallel circumstances as that of the two imperatives analyzed in the previous part.

Generally the sequential environment of these practices evaluated by the advice giver is not an explicit problematic one with no possible solution. That is not to say the sequential environment for the initiation of advice is only determined by the advice giver alone, on the contrary, the sequential environment is constructed by both parties, the perception, recognition or evaluation by the adviser are all closely relevant to the prior information provided by the advisee.

\subsubsection{Downgraded Explicit Problem}

\section{1) Explicit but downgraded problem}

One sequential position for these three practices is that a problem is explicitly displayed by the advisee, but either the advisee displays it in an alleviated/downgraded way (evidence in the turn construction) and recognized by the adviser or the adviser evaluates and assesses it as neither a serious nor urgent problem, sometimes even not a problem.

\section{Example 4}

120 SUS: ((sniff)) 䒝呀, 你们 我感觉 文学 特别 有 意思, 语言学 太枯燥 啦。

Aiya, nimen wo ganjue wenxue tebie you yisi, yuyanxue tai kuzao la. 
INT, you I feel literature especially have interesting, linguistics too boring PRT.

Oh my, you- I feel literature is especially interesting, linguistics is too boring.

$121 \mathrm{WEN}$ : $\uparrow$ 哪::了: 文学 也得 是一直 读 一直 看, 䒝呀, 感觉现在 连书

Nale, wenxue ye de shi yizhi du yizhi kan, aiya, ganjue xianzai lian shu

How can, literature also need Be all the time read all the time read, INT, feel now even book

How can, literature also need reading all the time,oh, my, I feel now I even

122

也买不起了, 都贵的.

ye maibuqi le, dougui de.

also afford N PRT, all expensive NOM.

can not afford books, all too expensive.

123 SUS: (hhenhh)你 还要 买原装的书, 你可以在网上买电子版

(hhenhh) Ni hai yao mai yuanzhuang de shu, ni keyi zai wangshang mai dianzi ban

(hhenhh)You still want buy original NOM book, you can on line buy electronic version

You still want to buy the original book? you can buy electronic version

124

的书呀.

de shu ya.

NOM book PRT.

book online.

$125 \quad(0.5)$

126 WEN: ((sniff)) 嗯, 电子版 的 有时候 看 吧想 做个笔记啥 的

En, dianzi ban de youshihoukan ba xiang zuoge biji sha de

Um, electronic version NOM sometimes read PRT want make C notes something NOM

$\mathrm{Um}$, sometimes when reading the electronic version, and (if I) want to make notes or

127 不方便.

bu fangbian.

$\mathrm{N}$ convenient.

something, it is not convenient.

Susan and Wendy in this telephone conversation are postgraduates majored in linguistics and literature respectively. Susan's assessment of two subjects at line 120 was responded with disagreement from Wendy on the painstaking reading in literature and the expensiveness of books at line $121-122$. The subsequent turn at line 123 by Susan was constructed first by a reversed polarity question (Koshik, 1999) through which buying the book was topicalized. The reversed polarity question indicated that there is no necessity in buying the original books, which put the presupposition of the problem in the prior turn into question as well as cast a doubt on the severity of the problem, or even doubt on whether it counted as a problem. This first TCU at line 123 undermined the explicit problematic sequential environment formulated in the prior turn. Thus the advice in you can... form was formulated under this sequential position different from that in the 3.1 section. The advice given in Section 3.1 immediately follows an explicit problem or follows a congruent recognition of the explicit problem, that is two parties achieve intersubjectivity in determining 
the nature of the problem. However, in this example, the two parties display different evaluation on the same problem, and Susan the advice-giver downgraded the severity of the problem first and then formulated her advice in a you can... form.

The following is a similar example of this class.

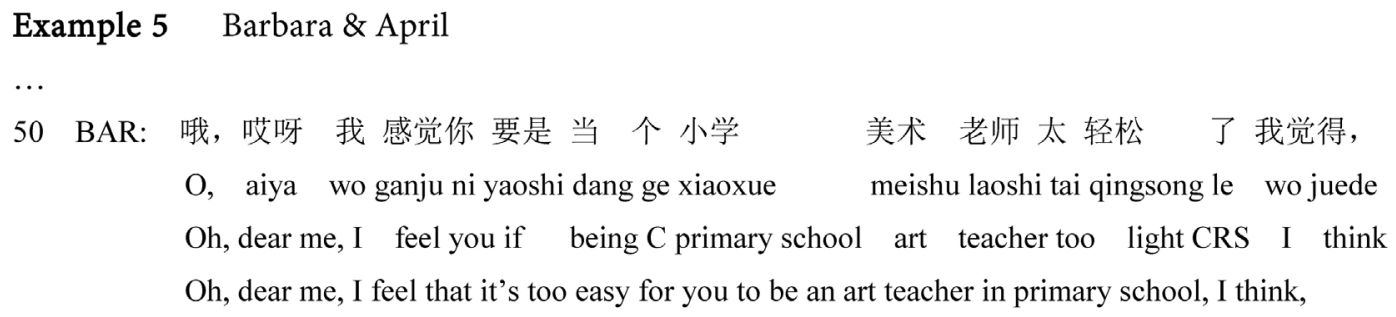

53 APR: [我 感觉 小学 (好像) 老师 应该 挣不下钱:

Wo ganju xiaoxue haoxiang laoshi yinggai zhengbuxiaqian

I feel primary school seem teacher should earn $\mathrm{N}$ money:

I feel it seems that in primary school a teacher should not be able to earn much money.

54 BAR: 挣不下钱 啊, 但是 好 轻松 呀哈, 你(.)可以

Zhengbuxiaqian a, danshi hao qingsong ya ha, ni keyi

earn N money PRT, but quite light PRT PRT, you can

earn little money, but quite light, you can

55 APR: 对,

$$
\text { Dui. }
$$

Right.

56

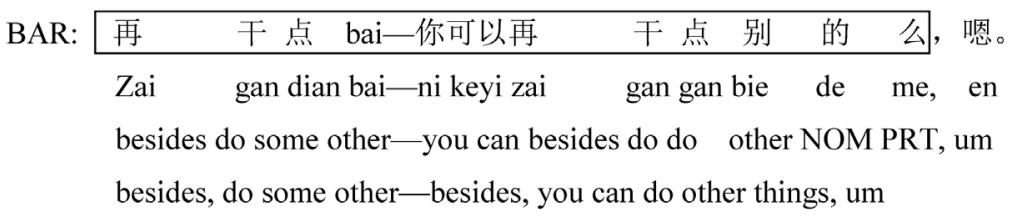

57 APR:

恩。

En.

Um.

In this conversation April was going to attend a teacher-qualification examination reluctantly and Barbara gave a positive assessment at line 50 on a teaching career in a primary school. However, April showed her worry to be a teacher in a primary school and began her turn with "I feel" which downgraded the epistemic stance in what she is going to say, and then employed the lexical choice of the words seem and should adding the uncertainty in what she stated. It is 
where explicit problem lies. Although the problem was downgraded, advice was elicited in the next turn. In the subsequent turn, Barbara first acknowledged the disadvantages of the career, but downgraded the severity of the explicit problem in the prior turn by emphasizing the salient advantages of being a teacher and gave advice to the solve April's worry. The advice is formulated in you can... form, which put less imposition on the recipient in a relatively softened and alleviated interactional situation.

\section{2) Explicit Problem with a Possible Solution}

The sequential environment in this part is that the problem is explicitly displayed coupled with a possible solution, however this possible solution is improper from the adviser's perspective.

\section{Example 6 \\ 107 CRY: \\ 哇塞, 你这每天吃 啥了。你家郭否没 给你 做 点 啥 好吃的? \\ Wasai, ni zhe meitian chi sha le. nijia Guolei mei gei ni zuo dian sha hao chi de? \\ INT, you this everyday eat what CRS. your Guolei N gave you cook some what good eat NOM? \\ Wow, what do you eat everyday? Doesn't your Guolei (husband) cook something good to eat?}

$108 \quad(1.0)$

109 DAI: 炒 大米, 炒大米, 炒大米, 炒大米, 炒大米。

Chao dami, Chao dami, Chao dami, Chao dami, Chao dami.

Fried rice, fried rice, fried rice, fried rice, fried rice.

110 CRY: $\uparrow$ 这可不行呀。

Zhe ke buxing ya.

This just N acceptable PRT.

This just can't do.

$111 \quad(0.5)$

112 DAI：然后 就是 然后 就是 “蔬菜”, 我 现在 吃不进去 肉.

Ranhou jiushi ranhou jiushi shucai, wo xianzai chi bu jinqu rou.

Then $\mathrm{BE}$ then $\mathrm{BE}$ vegetables, $\mathrm{I}$ now eat $\mathrm{N}$ in meat.

Then are then are vegatables, Now I can't eat meat.

$113 \quad(0.3)$

114 CRY: 唉, 我 跟 你说你得(.) 你得 多 补 上点, 趁你这段时间你不多

Ai, wo gen ni shuo ni de ni de duo bu shang dian, chen ni zhe duan shijian, ni bu duo

INT, I to you tell you need you need more mend up some, while you this $\mathrm{C}$ time, you N more

Alas, I tell you that you need, you need mend your body more, while this time, if you do not

115 补, 你咋呀你以后。

bu, ni za ya ni yihou,

mend, you what PRT you in the future,

mend yourself, what could you do in the future?

116 DAI: 我补啥了 么, 我吃啥 吐啥, 还补呢,

Wo bu sha le me, wo chi sha tu sha, hai bu ne,

I mend what CRS PRT, I eat what vomit what, still mend PRT.

What can I mend up, whatever I eat whatever I vomit, how can I mend up? 
Daisy was pregnant and Crystal was inquiring her diet, from a more general question to a specific question at line 107, which was responded with repetition of "fired rice" to describe a monotonous diet. Crystal assessed this situation as problematic at line 110. Subsequently, Daisy added "vegetables" to modify the extreme case formulation (Pomerantz, 1986; Edwards, 2000) and accounted why only "vegetables" added. The severity of the problem has alleviated due to a possible solution "vegetables", nevertheless, the problem still existed and turned into an alleviated one. Under this circumstance, the advice is delivered through an informing I tell you that you need... to benefit A's health condition, which disguised the imposition on Daisy, nonetheless, it was recognized as a piece of advice and it was overtly resisted by the infeasibility of the suggested action.

\section{Example 7}

031 FAN: .hh 然后 反正我同学 (.) 然后 就是 说(.)态度(.)挺 不好的。(Hhenhh)

Ran hou fanzheng wo tongxue ranhou jiushi shuo, taidu ting bu hao de, (Hhenhh)

Then anyway my classmate then only say manner very N nice NOM.

Then anyway my classmate told me that (her) manner was not very nice.

032 GRA: 昨:天:::,昨天呀。

Zuotian::: zuotian ya.

Yesterday, yesterday PRT.

Yesterday, yesterday?

033 FAN: (噢)。

O.

Oh.

034 FAN：对。昨天。

Dui, zuotian.

Right, yesterday.

035 GRA: 恩。

En.

Um.

$036 \mathrm{FAN}$ : 我 就 准备: 尽快回去。

Wo jiu zhunbei jinkuai huiqu.

I just prepare as soon as possible back.

I just prepare to go back as soon as possible.

037 GRA: 恩。行了吧。

En, xingle ba.

Um, Ok PRT.

Um, it's Ok.

038 FAN: 你 是 打算 啥时候 回呢?

Ni shi dasuan shashihou hui ne?

You BE plan when back PRT?

When do you plan to go back? 
039 GRA: 嗯, 我哈。我不是 就是买了公, 买了星期二的票 啦。

En, wo ha, wo bu shi jiushi mai le me, mai le xingqi'er de piao la

Um, I PRT. I N BE just buy ASP PRT, buy ASP Tuesday NOM ticket PRT.

Um, I, I bought, I bought the ticket for Tuesday.

040 FAN:

恩。

En.

Hum.

041 GRA: ((clearing throat))

042 FAN: 哦。那行。

Oh, na xing.

$\mathrm{Oh}$, that $\mathrm{Ok}$.

Oh, that's ok.

043 GRA: 恩。

En.

Um.

044 FAN: 我差不多 要 在 市里面 待两 天 可能 就是 星期二 或者 星期三。

Wo chabuduo yao zai shi limian dai liang tian keneng jiushi xingqi'er huozhe xingqisan.

I nearly need in city inside stay NUM day probably BE Tuesday or Wednesday.

I will stay in the city for two days, probably will be back on Tuesday or Wednesday.

045

.h 反正 这 两天 最- 最晚 就是 星期三。星期三早上. 回了。

Fanzheng zhe liang tian zui- zuiwan jiushi xingqisan, xingqisan zaoshang hui le.

Anyway this NUM day most-latest BE Wednesday Wednesday morning back CRS.

Anyway these two days, the latest is Wednesday. I'll be back in the Wednesday morning.

046 GRA: 噢。是吧。星期三。

O, shiba, xingqisan.

Oh, Be PRT, Wednesday.

Oh, is it, Wednesday?

047 FAN: 嗯。

En.

Um.

048 GRA: 我 觉得 星期三 你: 还是 星期二 吧。

Wo juede xingqisan ni haishi xingqi'er ba.

I think Wednesday you: had better Tuesday PRT.

I think Wednesday, you'd better (be back on) Tuesday.

049 GRA：你星期二 回去以后，忙活 忙活 事儿，星期三 (之后) 直接 找她去啦。

Ni xingqi'er huiqu yihou, manghuo manghuo shi'er xingqisan (zhihou) zhijie zhao ta qu la.

You Tuesday back after, be busy be busy things Wednesday after directly find her go PRT.

After you're back on Tuesday, you are busy with other things, after Wednesday you go directly

to find her.

050 FAN: 嗯。

En.

Um. 
Fanny and Grace are classmates and the paper they collaboratively did was rejected by the teacher. They were talking about going back to school together to have a talk with the teacher. Fanny announced her decision to go back as soon as possible at line 36 and asked the date when Grace was back at line 38. After she knew Grace's decision, Fanny reciprocally contributed her arrangement and demonstrated a possibility to go back on Tuesday or Wednesday, and added the latest possibility is Wednesday at line $44-45$. As for the problematic situation Fanny has already had the possible solutions to go back on Wednesday at the latest, but this possible solution was evaluated by the adviser as not a better one, and the advice was put forward in a more mild way. The advice was first formulated as I think Wednesday you: however, the stretched you worked as a pivot to construct the turn into another trajectory of advice you'd better Tuesday, accompanying with an account to legitimate her advice and the original formulation with Wednesday was abandoned. When the explicit problem occurs with a possible solution, apparently the problem would be solved in one way or another, the advice put forward is only to offer another more proper way to solve the advisee's problem.

\subsubsection{No Problem Displayed and Identified}

This sequential environment for these three practices refers to the interactional situation when no problem is displayed by the advisee and also no problem is identified by the adviser, which is the extreme case at one end of the gradient of the downgraded problem. However, the advice giver voluntarily initiates advice in order to benefit the advisee on a related thing touched off by the prior talk. Compared with the sequential environment in Section 3.1, no problem is displayed and identified, thus the sequential environment is not so demanding for a piece of advice as that of the imperatives. The piece of advice is put forward mainly on the advice giver's epistemic status on the related things and little on the demand of the sequential environment.

\section{Example 8 \\ $\cdots$ \\ 83 CHA: 啊: 是。 \\ A: shi. \\ Ah, yes.}

82 JAN : 还好 吧, 个现在(.)现在这种大城市交通 都很方便的。

Haihao ba, xianzai xianzai zhezhong da chengshi jiaotong dou hen fangbian de.

It's ok PRT, now this kind big city transportation all very convenient NOM.

It's ok, nowadays the transportation in this kind of big city is very convenient.

84 JAN : 只要 你 反正 是大城市 不管(.) 各种 交通 都很 方便,

Zhiyao ni fanzheng shi da chengshi buguan gezhong jiaotong dou hen fangbian,

As long as you anyway BE big city no matter various transportation all very convenient,

As long as you anyway in the big city no matter various kinds of transportation are all very convenient, 


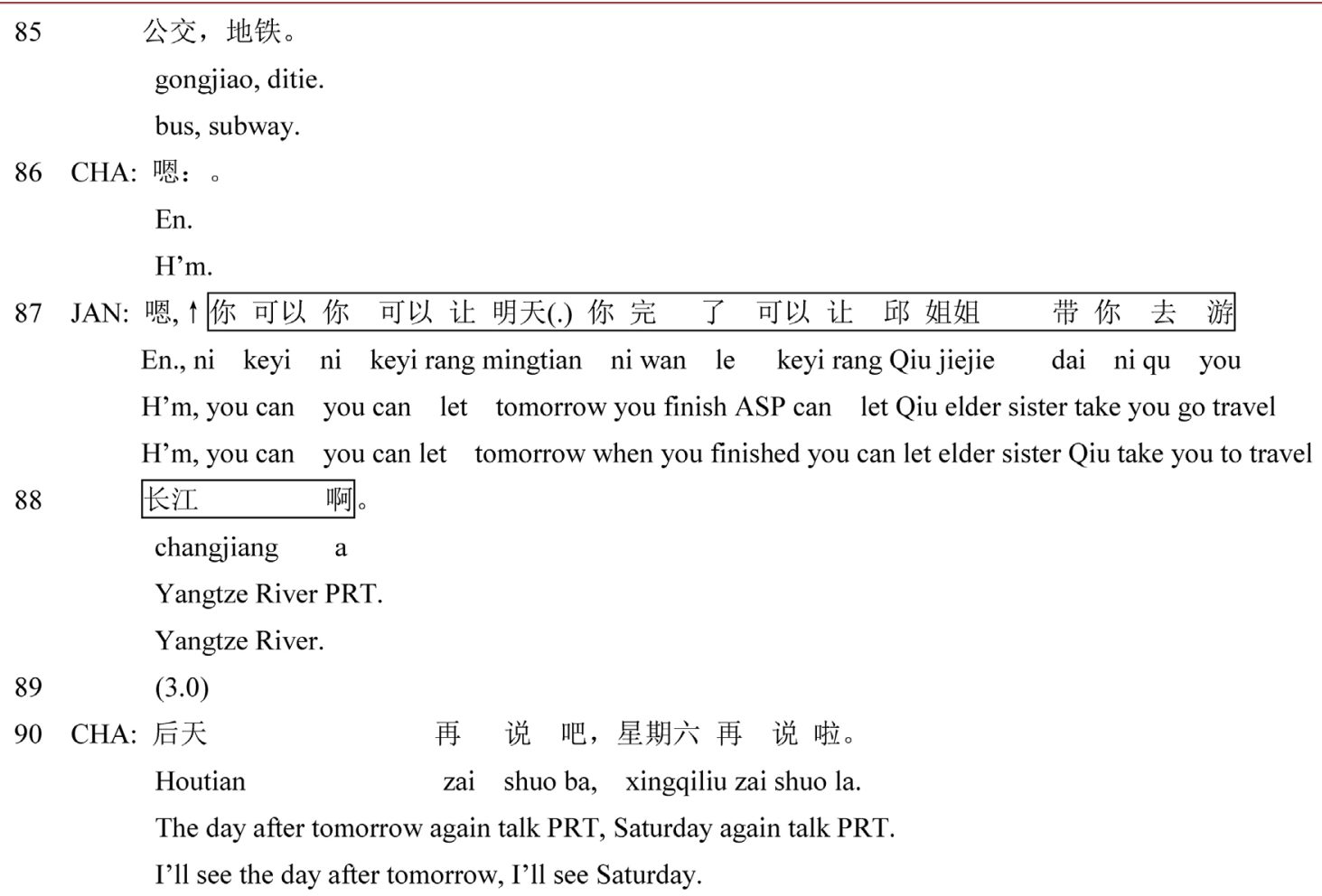

In this telephone conversation Charles said Wuhan is a long way from $\mathrm{Wu}$ chang in the previous talk, and Jane presented her disagreement accompanying with an account on the convenient transportation in big city at line $82,84-85$, which was responded with an agreement and a token of receipt at line 83 and 86 respectively. There was no indication in the preceding turns in this talk about the arrangement of Charles' itinerary tomorrow, and Jane initiated a piece of advice at line 87 on this touched-off topic out of the convenience in the transportation mentioned in the prior turn. This piece of advice is based on her prior knowledge: the Yangtze River is worth visiting and Sister Qiu could be a good tour guide. The advice was formulated as you can..., which offered a great contingency for the recipient to reject than an imperative. This practice only offered a possible agenda for the recipient to enrich or better Charles' journey in $\mathrm{Wu}$ han.

Next example is one representative of a class of examples in this part. When the advisee expresses a wish or a positive assessment of something, adviser gives advice to benefit advisee. In the following example, the advice is affiliative to the action in the prior turn.

\section{Example 9 (Dora and Judy)}

096 DOR: 看来 你 现在是正好 不忙?

Kanlai ni xianzai shi zhenghao bu mang?

It seems you now BE happen right $\mathrm{N}$ busy?

It seems that you happen not to be busy right now? 


\begin{tabular}{|l}
097 JUD: 我啊 我还好, 就是 每天 写 作业 啊。这不是(.)快 期末 \\
Wo a wo haihao, jiu shi meitian xie zuoye a, zhe bu shi kuai qomo \\
I PRT I all right, just BE everyday write homework PRT, now N BE soon end of term \\
I am alright, just do the homework everyday. It is the end of the term soon, \\
有 很多 论文 要 交, 好多 作业 要 交, 还好。 \\
you henduo lunwen yao jiao, haoduo zuoye yao jiao, haihao. \\
there are many papers need hand in, much homework need hand in, it's all right. \\
(We have) many papers to hand in, much homework to hand in, it's all right.
\end{tabular}

099 DOR: 啊=这 研究生呀真好, 咬呀, 我也想。

Ah, zhe yanjiusheng ya zhenghao, aiya, wo ye xiang.

PRT, this postgraduate PRT really good, PRT, I also want.

$\mathrm{Ah}$, postgradate is really good, oh my, I also want (to be a postgraduate.)

100 JUD:

((laughter))

101 JUD: 你 也 可以念一个 呀::你可以那个 停::那 叫 什么, “停薪留个职”,

$\mathrm{Ni}$ ye keyi nian yige ya ni keyi nage ting na jiao shenme ting xin liu zhi,

You also can study NUM C PRT you can that C stop that call what stop salary retain job,

You also can do a master degree, you can stop, what it called, retain job stop salary,

102 然后你 你 再 回来念。念了 以后回去, 你如果 要是 能 找到 更好 的,

ranhou ni ni zai huilai nian. Nian le yihou huiqu, ni ruguo yaoshi neng zhaodao genghao de,

then you you again back study. study ASP after back, you if in case can find out better NOM.

then you can come back to study again. When go back after graduate, if you can find a better job,

103

\begin{tabular}{ccccc}
\hline 你 不行 就 找, 找 不到 更好 的 还回 你们那儿呀。 \\
Ni bu xing jiu zhao, & zhao bu dao genghao de hai hui nimen na'er ya.
\end{tabular}

You $\mathrm{N}$ do just look for, find $\mathrm{N}$ out better NOM still return your there PRT.

Or, you just look for (a job), if you can not find a better one, return to your work place.

104 DOR: 嗯, 知道你的意思, 但是(.)现在 怎么 说, 嘆呀, 一 上 开 班 哇,

En, zhidao nide yisi, danshi xianzai zenme shuo, aiya, yi shang kai ban wa,

H'm, know your meaning, but now how say, INT once go start work PRT,

H'm, (I) know your meaning, but now how to say, Oh, my, as soon as I start to work,

105 它就(.)䒝呀, 吓 我一跳。一 上 开班 就(.)感觉 就不太 想

ta jiu aiya, xia wo yi tiao. Yi shang kai ban jiu ganjue jiu bu tai xiang

it just INT, frighten me NUM jump. Once go start work just feel just N too much want

it just, oh, my, scared me. Once I start to go to work, I just do not want too much to

106 回去念了。((laughter))

huiqu nian le.

go back study PRT.

go back to study.

The following is another similar example, in which the advisee does not display any problem, and the adviser also does not identify anything as an explicit problem. Nevertheless, when the adviser disagrees or disaffiliates with the advisee, the advice is also put forward based on the adviser's epistemic status on the matter and evaluation of the current situation of the advisee. Disagreement or 
the disaffiliation is implicative in the advice in these cases. The sequential environment for the advice is that the adviser evaluated the advisee's situation is not a good or a correct one which also account for the disaffiliative nature of advice in this type of advices.

\section{Example 10}

34 ROS: 萨:摩:耶::,

那 你 给它 起 什么 名字?

Samo ye,

na ni gei ta qi shenme mingzi?

Name(breed of dog), then you give it give what name?

Samoyed, then what name you give to it?

35 MER: .hhh安仔。

.hhh An Zai.

.hhh An cub

.hhh Anzai.

$36 \quad(0.5)$

37 ROS: 为什么要叫安仔。

Weishenme yao jiao Anzai.

Why want call Anzai.

Why do you want to call it Anzai.

38 MER: 因为它之前那个主人家里边儿叫它安仔。.hhh 然后我也不想给 Yinwei ta zhiqian na ge zhuren jia libian'er jiao ta Anzai. .hhh ranhou wo ye bu xiang gei Because it previous that $\mathrm{C}$ owner home inside call it Anzai. .hhh then I also $\mathrm{N}$ want give Because it was called Anzai in the previous owner's home, and then I also do not want to

39 它 换 名字。 ta huan mingzi. it change name. change its name.

$40 \quad(0.6)$

41 ROS: $\uparrow$ 噢。

O.

Oh.

42 MER: .tch我 觉得你说 它都, 它都离开那家主人了, 然后再给它 .tch wo juede ni shuo ta dou, ta dou likai na jia zhuren le, ranhou zai gei ta .tch I think you say it already, it already leave that house owner ASP, then further gave it I think, you say, it has already left that owner and then further

43 换个名字 不太好。

huan ge name bu tai hao.

change $\mathrm{C}$ name $\mathrm{N}$ too good.

I change its name, which is not good.

44 ROS: 嗯。

En.

Um. 


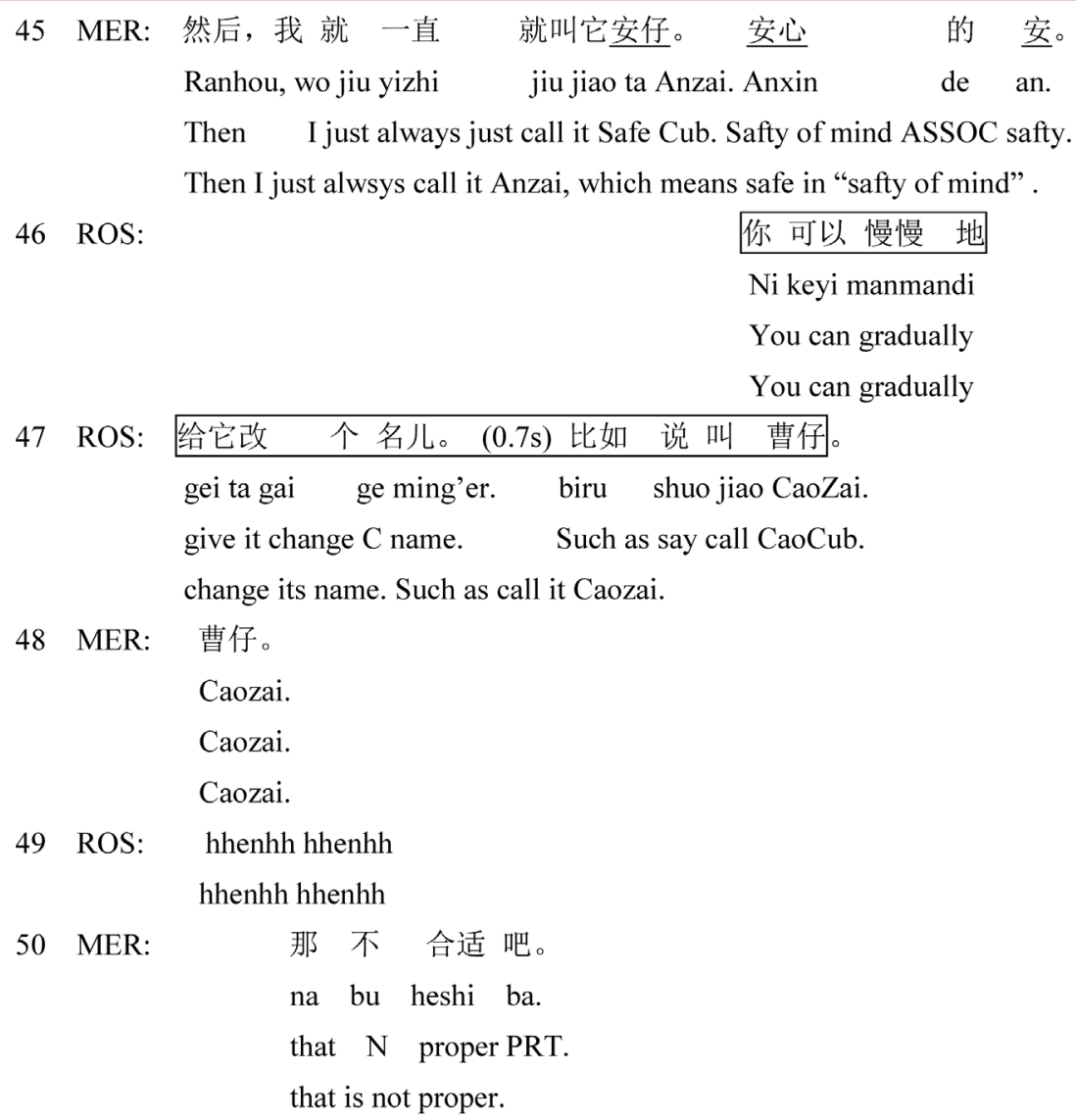

Rose and Merry were talking about the dog Merry recently got. Rose inquired the name of the dog and the account of the naming at line 34 and line 37 separately. Merry responded that the name was kept from the previous owner and accounted for not changing its name. The formulation of Merry's turn did not display that keeping the prior name has any problem; on the contrary, it was good for the dog according to Merry's account. Nevertheless, Rose still put forward a piece of advice in this sequential position for the sake of Merry based on Rose's own knowledge in her epistemic territory "it is normative for a dog having a new name given by the new owner". This syntactic pattern downgraded the imposition on Merry with a modal verb can, and was disaffiliative with Merry's will and action obviously. The sequential environment is unfavorable to entitle Rose enough rights to let Merry change the dog's name despite for Merry's sake, in that there is no problem (or a probmatic situation with a convenient solution, to adopt the prior name) for the advisee and the advice is going to be disaffiliative. This case is border case between no problem and the problem with a possible solution. It hedges the border, but as for these three declarative-typed advice, the sequential environment takes on a gradient distribution, not a clear-cut or divided, discrete, separated thing.

The two parties in the conversation take an opposite stance on the naming. The adviser Rose is oriented to her own evaluation of the situation as proble- 
matic (not good or not correct) to put forward a piece of advice. However, because the advisee does not display any problem and the adviser also do not identify the thing as an explicit problem, the advice is only put forward as disaffiliative, which does not have the strong imposition as the imperatives.

Example 8, 9, 10 are all the cases when the advisee does not display an explicit problem and at the same time the adviser also does not identified an explicit problem. Nevertheless the nuanced differences still lies in the sequential environment of advice. In the example 10 the advice is disaffiliative to the prior turn, and in the example 9, the advice is affiliative to the prior turn, and in the example 8 , the advice is on a touched-off topic, no overt affiliation or disaffiliation could be discussed. The sequential environment of these examples is on a gradient. One end of the gradient is no problem and the other end of the gradient is explicit problem with no solution.

The demanding degree of the advice in these examples:

\begin{tabular}{ccc} 
No problem & Downgraded explicit problem & Explicit problem \\
\hline Eg8, Eg9 $<$ Eg10 & $<$ Eg5,6,7
\end{tabular}

Example 10 is a border case hovering over the "no problem" and "explicit problem with a possible solution", in that a piece of disaffiliative advice displays that the adviser's evaluation of the situation is not suitable, however the advisee already has a "possible solution" and does not regard the "problem" from adviser's perspective as a problem. Example 10 blurred the border between the sequential environments in Section 3.2.1 and 3.2.2.

The sequential environment in Section 3.2, both downgraded explicit problem and no problem, is not so demanding for a piece of advice as that of the explicit problem with no solution.

\section{Discussion}

\subsection{The Relation between Syntactic Forms of Advice and Their Sequential Environment}

As is known to all, advice-giving is an other-attentive action, therefore, advice-giver is sensitive to the advisee's situation no matter it is an explicit problem or not. According to the analysis of the sequential positions of these practices where the unsolicited advice is delivered, we found that they demonstrate distinctive sequential features from each other. The imperative formatted advice (you do $X$, do $X$ ) frequently are employed in the sequential environment when an explicit problem is displayed by the advisee or identified by the adviser and above all no solution has come up yet, that is, where a possible solution is urgently demanded. Imperative formatted advice seldom occurs alone at the sequential environment of downgraded problem or no problem in Section 3.2. The other three practices you can..., I think that you..., I tell you that..., which explicitly give advice are always employed when the sequential environment is a downgraded problematic one or no problem, seldom do they appear imme- 
diately after an explicit problem without any possible solution.

Distinguished from the institutional advice given by the nurses to the patients in Leppanen's study (1998), the adviser has an orientation to be attentive to the interactional situation emerged in the interaction and the advice is put forward according to the adviser's evaluations and assessment of the situation at that moment in the interaction. Therefore if the situation the advisee displayed is no problem, and also there is no explicit problem identified by the adviser, then the adviser sheerly put forward advice to benefit the advisee based on the adviser's epistemic status. This kind of sequential environment per se do not call for advice, that is, the occurrence of advice is not as necessary as that of imperatives. If the interactional situation is a downgraded explicit problem, the sequential environment for the advice is obviously not as urgent as that of imperatives. The investigation further validates that syntactical forms that employed by the adviser is sensitive to their sequential environment, and this distributional pattern is closely related to the adviser's orientation to the evaluation of the problematic situation in a specific sequential environment.

\subsection{Deontic Rights under the Syntactic Forms}

Deontic rights refer to the capacity of an individual to determine action (Stevanovic, 2018), which is used to describe the underlying local power existing in the social interaction. What we could see at surface is the adviser initiated an action to let the advisee do a suggested action in the future and what underneath is the adviser's local power playing at the level of moment-by-moment unfolding of the social interaction.

Under the particular sequential environment of advice when the advisee in the interaction contributes something problematic or even of no problem, the adviser as the a listener is made immediate involvement in the interaction out of morality, however advice-giving is a delicate issue to deal with due to its nature and its agent to commit the action, and how much deontic rights the adviser is entitled to have has to be taken into consideration when the advice is formulated. The sensitivity reflected on the construction of a particular syntactic form of advice to the different sequential environment is a demonstration and display of sensitivity in adviser's deontic rights under the different sequential environment.

As shown in Figure 1, sequential environment is crucial in the conversation analysis, which is an important element in constructing and invoking the speaker's deontic rights and which also plays a dominant role in the construction of the syntactic forms the speaker is going to employ to deliver advice. In case the adviser is involved in a situation when the explicitly problematic situation is displayed, perceived or recognized, then more moral obligation and more deontic rights are invoked to help the advisee. By contrast, in case when the advisee displays no problem or the problem is downgraded, less moral obligation and less deontic rights are invoked in the interaction. 


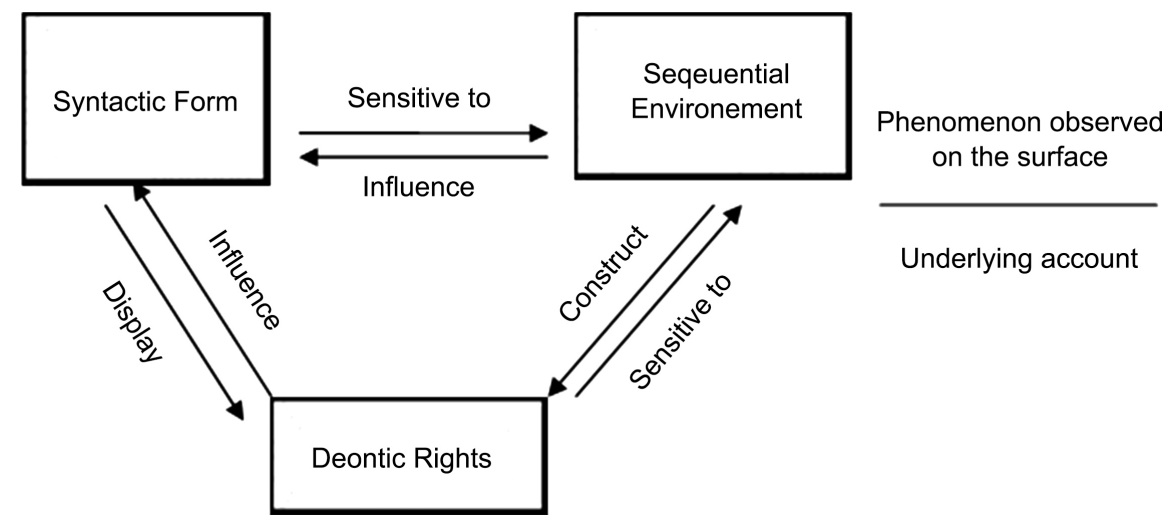

Figure 1. Triangle relations among the syntactic form, sequential environment and deontic rights.

Syntactic form of advice is a display of the underlying deontic rights in the interaction. Advice in the two imperative formats in its distinctive sequential environment displays the high entitlement of the advice-giver with more deontic rights to get the advisee to do the suggested action, in contrast, advice in the other three formats employed in a milder problematic situation demonstrates the relative low entitlement of the advice-giver with less deontic rights to get the advisee to do something in the future. For example: the modal verb can leaves the contingency on the advisee to do the suggested action; I think downgrades the deontic rights into a personal opinion, which is up to the advisee to decide whether or not to take the suggested action; I tell you also takes a weak deontic stance to frame the advice into an informing, mitigating the imposition on the advicee to do the suggested action. These three syntactic formats in nature have less imposition on the advisee to do something than the imperatives, which is also in accordance with the deontic rights distribution in advice-giving sequential environment.

The sequential environment is constructed turn-by-turn by the two parties in the interaction. Sometimes the intersubjectivity is achieved, and there is congruence in the evaluation and assessment of the problem from the adviser and the advisee, that is, what the advisee displays is also perceived or recognized by the adviser to almost the same extent. However, sometimes when the intersubjectivity is not achieved, the adviser is oriented to his/her own knowledge to made the evaluation of situation and put forward the advice mainly according to his/her epistemic basis, which is also the basis of his deontic right (Stevanovic \& Peräkylä, 2012).

As far as unsolicited advice in this paper concerned, the interaction most occur in the daily mundane conversation between peers, classmates, family members, colleagues, the identity and other social variants is not always the dominant element in these advice-givings. What is more important is the local power in the step-by-step unfolding of the interaction, the deontic right. It is greatly influenced by the sequential environment and the advice-giver's epistemic status in these mundane interactions. 


\subsection{Deviate Cases Analysis}

As usual CA research steps, our research went over the first step of CA analysis "the inductive search for regularity" (Heritage, 1988) and we established a pattern with the most typical cases. Then we come to the second step to conduct the deviant cases analysis. What deviant cases could indicate?

The deviate cases are found in our study. There are cases when the practices do $X$ and you do $X$ are employed to deliver advice in the sequential environment of downgraded problem or no problem mentioned in Section 3.2.

Advice in you do $X$ format in the following example is put forward after a possible solution had appeared. Nevertheless, the advice is still put forward in an imperative form accompanied with an account.

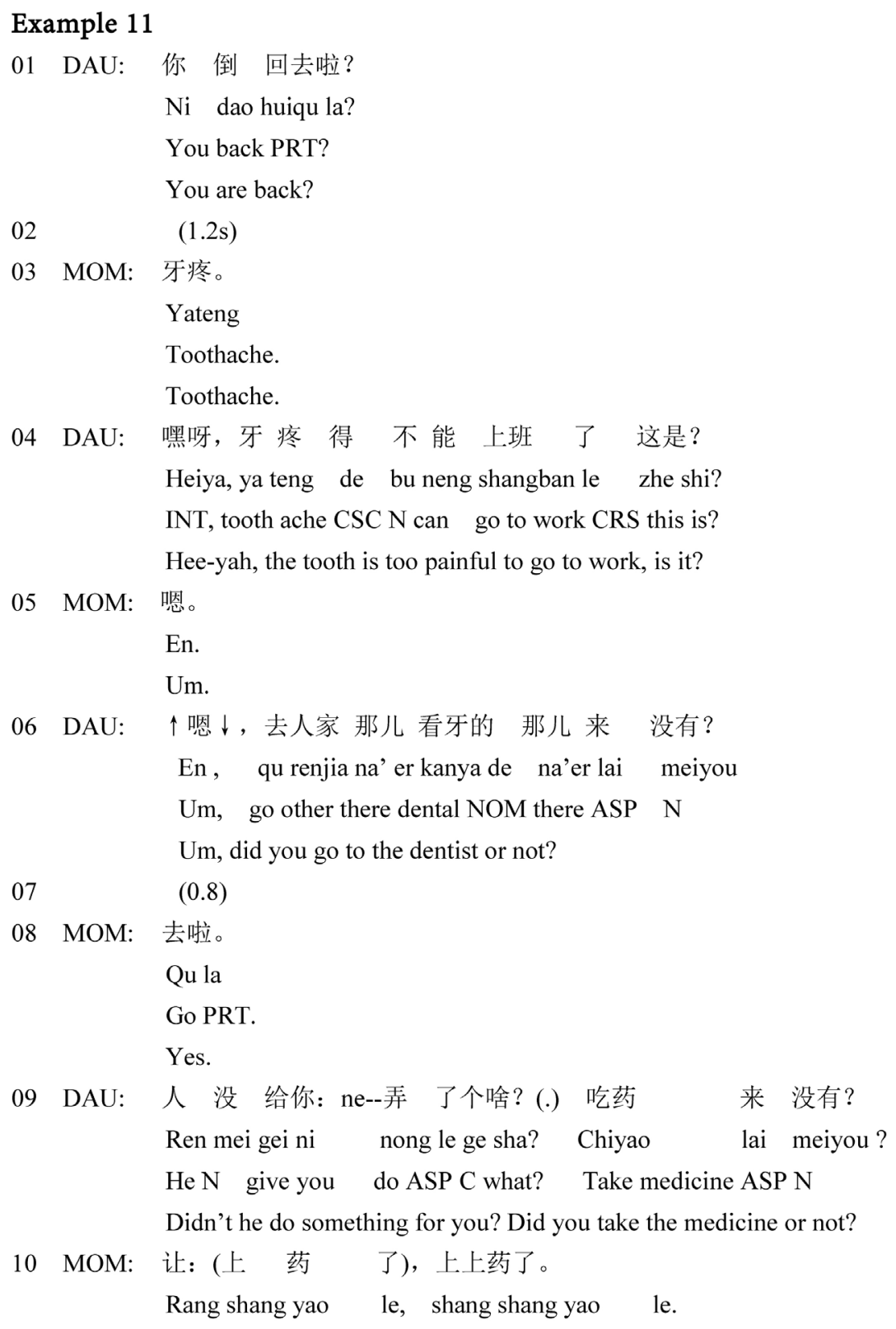


Let apply medicine PRT, apply up medicine ASP.

Let me apply the medicine, and I have applied the medicine.

$11 \mathrm{DAU}$ : 哦, 嗯: 那你 就上上 药 吧, 你喝 那(.)下火 的那东西了

Ao, en na ni jiu shang shang yao ba, ni he na xiahuo de na dongxile

Oh, um. then you just apply up medicine PRT, you drink that down the fire NOM that things CRS

Oh, um. then you just apply the medicine.(you) drink something to down the fire inside,

12

$\begin{array}{llllll}\text { 么, 下 } & \text { 火自然 } \text { 就(.) } & \text { 泡 也 } & \text { 下去了。 } \\ \text { me, xia le huo ziran jiu } & \text { pao ye xiaqu le. }\end{array}$

PRT. down ASP fire of course right after blister also go down CRS.

If the fire is down inside, then the blister will also go down.

13 MOM: 恩。

En.

Um.

The daughter's declarative question at line 1 was answered by mom's account for home. The non-type-conformed answer (Raymond, 2000) touched off an inquiry initiated by the adult daughter which at the same time displayed her inference on the severity of the toothache. The daughter's subsequent inquiry at line 6 and line 9 on the treatment condition demonstrated that her mother had already treated by the doctor. The first sentential TCU at 11 indicated the daughter's agreement of the doctor's treatment. In this example, the problem is mother's toothache and the possible solution by the doctor is proper and agreed by the daughter.

According to the regularity we just found, it is not the normative sequential position for an imperative You drink something... to deliver advice because there was already a possible solution to the problem, moreover, the possible solution was given by the dentist, which would be the proper solution. Although the effect of the medicine may not work immediately, the severity of the problem has been downgraded. However, a piece of advice was put forward in an imperative format and the causal relationship between the imperative and the prospective results was emphasized in the account immediately following the advice.

When the occurrence of the advice in imperatives is not a normative phenomenon, account is needed. The account here downgrades the deontic rights in imperatives and also legitimates an imperative employed in this sequential position. The more deontic rights the adviser is entitled to give a piece of advice, the less the adviser's need to account for his/her action of advice-delivery. Without account, the imperative alone to do the advice may take a risk of being unaccountable in this sequential position, and the imperative of advice may turn into an order, a command or an instruction.

In the next example, no explicit problem is displayed by the advisee, but an imperative format advice is delivered. In this situation, accounts are accompanying with the advice in an imperative form to bolster the viability of the advice in this sequential environment (Waring, 2007). 


\section{Example 12}

01 JEA: 回去再 说 吧, 那个, 恩: : 哦, 我周末 去苏宁看一下。

Huiqu zai shuo ba, na ge, en, oh, wo zhoumo qu Suning kan yi xia.

Back again talk PRT, that C, um, oh, I weekends go Name see NUM C.

Let's talk that again when I am back, um, oh, I want to go to Suning at weekends.

02 JEN: 恩。

En.

Um.

$03 \mathrm{~J}$ : 苏宁, 还有那个: (.) 北边儿那边儿。

Suning, haiyou na ge beibian'er nabian'er.

Name, and that $\mathrm{C}$ north there.

Suning, and north of city.

$21 \mathrm{JEA}$ : 解放 远呢, 那个, 关键 是(.)我还想 去看看 那 个王力门儿, 那个王力 Jiefang yuan ne, na ge, guanjian shi wo hai xiang qu kankan na ge Wangli men'er, na ge Wangli Name far PRT. that C, the key BE I also want go see see that C Name door, that C Name Jiefang Street is far away, that is, the key is I also want to have a look at Wangli Door, that Wangli

22 门儿 可能 在(.)胜利 桥 东 [那头了. men'er keneng zai Shengli qiao dong na tou le.

Door may be at Name Bridge East that end PRT.

Door may be at the end of the East Shengli Bridge.

23 JEN

那你 妈妈看 来 着,
Na ni mama kan lai zhe.
That your mom see ASP ASP.
Your mom has seen that.

$24 \mathrm{JEA}$ : 噢, 你们是在咱们那边看的么。

$\mathrm{O}$, nimen shi zai zanmen na bian kan de me

Oh, you Be at our that side see NOM PRT。

Oh, you saw it at our hometown,.

25 JEN: 䍐。

En.

Hum.

$26 \mathrm{JEA}$ : 我的 意思 是周末 我去一下: 胜利 桥 东 看一下他们总店 Wo de yisi shi zhoumo wo qu yi xia shengli qiao dong kan yi xia tamen zongdian I NOM meaning BE weekends I go NUM C Name Brideg East see NUM C their main store I mean that I go to East Shengli Bridge at weekends, to their main store to see

的门。 de men.

NOM door.

the doors.

$27 \mathrm{JEN}$ : 你:你先 看 那个苏宁电器吧, 人家十八号搞活动了。

Ni ni xian kan nage Suning dianqi ba, renjia shiba hao gao huodong le.

You first see that C Name electrical appliances PRT, they $18^{\text {th }}$ make sale CRS.

(You) go to Suning Electrical Appliance first, they will make sale on the $18^{\text {th }}$. 
Jean and Jennifer are sisters. Jean lives in the city and Jennifer lives with their mother in the hometown. Jean was going to buy some electrical appliances and security door for the family and wanted to do some preliminary survey in the city at weekends. Jean asserted her decision "to go to Suning" and "North" at line 1 and line 3, and Jennifer initiated a side sequence to discuss with Jennifer about the specific location of Suning. After this side sequence, Jean reasserted her plan to go to the door mainstore in the North as well at weekends to do the survey of the door. No explicit problem displayed by Jean. Jennifer informed Jean the fact that their mom has already done the survey on security doors which indicated unnecessity for Jean going to the door shop, serving as an account before the advice to identify the potential problem (Waring, 2007). Jean undermined the rationality of this account by claiming the fact that mom did the survey in the hometown rather than in the city, which validated the necessity in Jean's action.

The problem is not explicitly displayed or stated all through in this case. The accompanied account after the advice downgrades the Jennifer's deontic rights in advice delivery and deontic authority in imperatives (Stevanovic \& Peräkylä, 2012) to bolster the viability of the advice (Waring, 2007).

Compared with the typical advice in imperatives, the imperatives in Section 3.1 could do the advice alone registering a kind of deontic rights which need not provide any account for her initiation of the advice-giving. The imperatives in the examples like the above ones in Section 4.3. When they occur in a milder problematic situation, accounts are accompanied to downgrade deontic rights in the advice in imperative, and to legitimate its occurrence in this kind of sequential environment.

If the imperatives appear in this kind of sequential environment without any account, there is a risk that the advice is interpreted into a command or an order, which leaves no contingency for the recipient to refuse the action, which is against the action ascription and action formation of advice in nature (Levinson, 2013). The deviant cases are a strong evidence to prove the regularities of the sequentially-specific practices of advice: if the imperative-typed advice appears at the sequential environment of the declarative-typed advice, imperative alone is not a piece of advice in the interaction.

In sum, though the inductive research of the typical advice in imperatives and the declaratives and then a research on the deviate cases, we conclude that different syntactic formats employed to deliver advice displays a difference distribution in their sequential environment, which is closely related to the speaker's orientation to deontic rights to give advice on a particular sequential position. Generally, advice in imperative formats like you do $X$ and do $X$ displays relatively more deontic rights to let the advisee do the suggested action compared with the rest other three formats. The deviate cases we found only in imperatives also justified the regularity. When the advice in imperative occurs in a non-normative sequential environment for imperatives, then account is accom- 
panied to downgrade the deontic rights and to legitimate the occurrence of imperatives in a certain sequential environment.

\section{Conclusion}

The advice is invoked to benefit the advisee; therefore it is a pro-social altruistic action per se to maintain the social solidarity and social cooperation. Apart from this feature, advice-giving as another-attentive action also has a close relation with deontics. The core feature of the advice-giving is to get the advisee to do something, which is also where deontic rights lies. We investigated the sequential environment which is one of the constitutive elements to entitle the adviser the deontic right to give a piece of unsolicited advice (other constitutive elements including epistemic basis etc.) and concluded the distributional features of two kinds of different syntactical forms also display different deontic rights in giving advice.

This study only focuses on the distributional relationship of the syntactical formats and their sequential features in the unsolicited advice, and further investigation can be conducted on the solicited advice, in that, in the solicited condition, the adviser is already put in a position of deontic authority, which may take on distinctive features in giving advice. Besides, since the syntax is the research object in this paper, we take the other three practices as a whole to do the comparison with the two imperative practices. Further study could be conducted on the more specific practices of advice-giving and multimodal analysis of the advice-giving in the interaction.

This study enriches the grammar of spoken Chinese when doing the advice-giving and provides a basis study for the comparative studies of advice-giving in different languages. Moreover, this study could also provide a new perspective of further research on the other practices of advice-giving, such as my side telling, interrogative typed advice etc. in Mandarin daily conversation. Besides, the study of advice in mundane conversation also provides a foundation for the further study of advice in the institutional talk, such as conversation in the consultation, in the hospital, in the helpline etc. The regularity we found in the research also has practical significance in guiding people to employ the proper syntactic form to do the advice-giving in the daily conversation so as to create a harmonious personal relationship.

\section{Note}

This research is a part of a projection "A conversational analysis of suggestion sequence in daily talk-in-interaction" in the "Thirteenth Five-Year" Planning Projects in 2016 sponsored by the Institute of Education Sciences, Shanxi province, China (Grant No. GH-16174). It is also funded by Research Project Supported by Shanxi Scholarship Council of China (Project Number: 2016-016).

\section{Conflicts of Interest}

The author declares no conflicts of interest regarding the publication of this paper. 


\section{References}

Atkinson, J. M., \& Heritage, J. (1984). Structures of Social Action: Studies in Conversation Analysis. Cambridge: Cambridge University Press.

Brown, P., \& Levinson, S. C. (1987). Politeness: Some Universals in Language Usage. Cambridge: Cambridge University Press. https://doi.org/10.1017/CBO9780511813085

Butler, C. W., Danby, S., Emmison, M., \& Thorpe, K. (2009). Managing Medical Advice Seeking in Calls to Child Health Line. Sociology of Health and Illness, 31, 817-834. https://doi.org/10.1111/j.1467-9566.2009.01179.x

Butler, C. W., Potter, J., Danby, S., Emmison, M., \& Hepburn, A. (2010). Advice Implicative Interrogatives: Building "Client-Centered Support" in a Children's Helpline. Social Psychology Quarterly, 73, 265-287. https://doi.org/10.1177/0190272510379838

Couper-Kuhlen, E. (2014). What Does Grammar Tell Us about Action. Pragmatics, 24, 623-647. https://doi.org/10.1075/prag.24.3.08cou

Curl, T. S. (2006). Offers of Assistance: Constraints on Syntactic Design. Journal of Pragmatics, 38, 1257-1280. https://doi.org/10.1016/j.pragma.2005.09.004

Curl, T. S., \& Drew, P. (2008). Contingency and Action: A Comparison of Two Forms of Requesting. Research on Language and Social Interation, 41, 129-153. https://doi.org/10.1080/08351810802028613

Drew, P. (2005). Conversation Analysis. In K. L. Fitch, \& R. E. Sanders (Eds.), Handbook of Language and Social Interaction (pp. 71-102). Mahwah, NJ: Lawrence Erlbaum Associates.

Drew, P. (2013). Conversation Analysis and Social Action. Journal of Foreign Languages, 36, 1-19.

Edwards, D. (2000). Extreme Case Formulations: Softeners, Investment, and Doing Nonliteral. Research on Language and Social Interaction, 33, 347-373.

https://doi.org/10.1207/S15327973RLSI3304_01

Emmison, M., \& Firth, A. (2012). Requesting and Receiving Advice on the Telephone: A Comparative Analysis of Some Australian-Based Helplines. In H. Limberg, \& M. A. Locher (Eds.), Advice in Discourse (pp. 213-232). Amsterdam: Benjamins. https://doi.org/10.1075/pbns.221.13emm

Heritage, J. (1988). Explanations as Accounts: A Conversation Analytic Perspective. In C. Antaki (Ed.), Analysing Everyday Explanation: A Casebook of Method (pp. 127-144). London: SAGE.

Heritage, J. (2005). Conversation Analysis and Instituational Talk . In K. L. Fitch, \& R. E. Sanders (Eds.), Handbook of Language and Social Interaction (pp. 71-102). Mahwah, NJ: Lawrence Erlbaum Associates.

Heritage, J., \& Lindström, A. (1998). Motherhood, Medicine, and Morality: Scenes from a Medical Encounter. Research on Language and Social Interaction, 31, 397-438. https://doi.org/10.1207/s15327973rlsi3103\&4_5

Heritage, J., \& Lindström, A. (2012). Advice Giving-Terminable and Interminable: The Case of British Health Visitors. In H. Limberg, \& M. A. Locher (Eds.), Advice in Discourse (pp. 169-194).Amsterdam: John Benjamins. https://doi.org/10.1075/pbns.221.11her

Heritage, J., \& Raymond, C. W. (2016). Are Explicit Apologies Proportional to the Offenses They Address? Discourse Process, 53, 5-25. https://doi.org/10.1080/0163853X.2015.1056695

Heritage, J., \& Sefi, S. (1992). Dilemmas of Advice: Aspects of the Delivery and Reception of Advice in Interactions between Health Visitors and First Time Mothers. In P. Drew, 
\& J. Heritage (Eds.), Talk at Work (pp. 359-419). Cambridge: Cambridge University Press.

Heritage, J., Raymond, C. W., \& Drew, P. (2019). Constructing Apologies: Reflexive Relationships between Apologies and Offenses. Journal of Pragmatics, 142, 185-200. https://doi.org/10.1016/j.pragma.2019.01.001

Jefferson, G., \& Lee, J. (1992). The Rejection of Advice: Managing the Problematic Convergence of a "Troubles-Telling" and a "Service Encounter". In P. Drew, \& J. Heritage (Eds.), Talk at Work (pp. 521-548). Cambridge: Cambridge University Press.

Kendrick, K. H., \& Drew, P. (2016). Recruitment: Offers, Requests, and the Organization of Assistance in Interaction. Research on Language and Social Interaction, 49, 1-19. https://doi.org/10.1080/08351813.2016.1126436

Kinnell, A. M., \& Maynard, D. (1996). The Delivery and Receipt of Safer Sex Advice in Pre-Test Counseling Sessions for HIV and AIDS. Journal of Contemporary Ethnography, 24, 405-437. https://doi.org/10.1177/089124196024004002

Koshik, I. (1999). Beyond Rhetorical Questions. Amsterdam: John Benjamins Publishing.

Leppanen, V. (1998). The Straight forwardness of Advice: Advice-Giving in Interactions between Swedish District Nurses and Patients. Research on Language and Social Interaction, 31, 209-239. https://doi.org/10.1207/s15327973rlsi3102_3

Levinson, S. C. (2013). Action Formation and Ascription. In J. Sidnell, \& T. Stivers (Eds.), Handbook of Conversation Analysis (pp. 103-130). Malden, MA: Wiley-Blackwell. https://doi.org/10.1002/9781118325001.ch6

Lindström, A. (2005). Language as Social Action: A Study of How Senior Citizens Request Assistance with Practical Tasks in the Swedish Home Help Service. In A. Hakulinen, \& M. Selting (Eds.), Syntax and Lexis in Conversation (pp. 209-233). Amsterdam: Benjamins. https://doi.org/10.1075/sidag.17.11lin

Martinez-Flo, A. (2005). A Theoretical Review of the Speech Act of Suggesting: Towards a Taxonomy for Its Use in FLT. Revista Alicantina de Estudios Ingleses, 18, 167-187. https://doi.org/10.14198/raei.2005.18.08

Mondada, L. (2013). The Conversation a Analytic Approach to Data Collection. In J. Sidnell, \& T. Stivers (Eds.), The Handbook of Conversation Analysis (pp. 32-56). Malden, MA: Blackwell. https://doi.org/10.1002/9781118325001.ch3

Pomerantz, A. (1986). Extreme Case Formulations: A Way of Legitimizing Claims. $\mathrm{Hu}$ man Studies, 9, 219-229. https://doi.org/10.1007/BF00148128

Randall, D. (1995). "Doing” Mother-Daughter: Conversation Analysis and Relational Contexts. In T. J. Socha, \& G. H. Stamp (Eds.), Parents, Children and Communication: frontiers of Theory and Research (pp. 113-125). Mahwah, NJ: Lawrence Erlbaum Associates, Inc.

Raymond, G. (2000). The Structure of Responding: Type-Conforming and Nonconforming Responses to Yes/No Type Interrogatives. Ph.D. Dissertation, Los Angeles, CA: Department of Sociology, UCLA.

Sacks, H. (1995). On Suicide Threats Getting Laughed Off. In G. Jefferson (Ed.), Lectures on Conversation Volume I \& II Part I (pp. 12-20). Hoboken, NJ: Blackwell Publishing.

Searle, J. R. (1969). Speech Acts: An Essay in the Philosophy of Language. Cambridge: Cambridge University Press. https://doi.org/10.1017/CBO9781139173438

Searle, J. R. (1979). Expression and Meaning: Studies in the Theory of Speech Acts. Cambridge: Cambridge University Press. https://doi.org/10.1017/CBO9780511609213

Shaw, C. (2013). Advice Giving in Telephone Interactions between Mothers and Their 
Young Adult Daughters. Doctoral Dissertation, Loughborough: Loughborough University.

Shaw, C., Potter, J., \& Hepburn, A. (2015). Advice-Implicative Actions: Using Interrogatives and Assessments to Deliver Advice in Mundane Conversation. Discourse Studies, 17, 317-342. https://doi.org/10.1177/1461445615571199

Stevanovic, M. (2018). Social Deontics: A Nano-Level Approach to Human Power Play. Journal for the Theory of Social Behaviour, 48, 369-389. https://doi.org/10.1111/jtsb.12175

Stevanovic, M., \& Peräkylä, A. (2012). Deontic Authority in Interaction: The Right to Announce, Propose and Decide. Research on Language and Social Interaction, 45, 297-321. https://doi.org/10.1080/08351813.2012.699260

Vehviläinen, S. (2009). Student-Initiated Advice in Academic Supervision. Research on Language \& Social Interaction, 42, 163-190. https://doi.org/10.1080/08351810902864560

Vehviläinen, S. (2012). Question-Prefaced Advice in Feedback Sequences of Finnish Academic Supervisions. In H. Limberg, \& M. A. Locher (Eds.), Advice in Discourse (pp. 31-52). Amsterdam: Benjamins. https://doi.org/10.1075/pbns.221.04veh

Waring, H. Z. (2007). The Multi-Functionality of Accounts in Advice Giving. Journal of Sociolinguistics, 11, 367-391. https://doi.org/10.1111/j.1467-9841.2007.00328.x

Waring, H. Z. (2012). The Advising Sequence and Its Preference Structures in Graduate Peer Tutoring at an American University. In H. Limberg, \& M. A. Locher (Eds.), Advice in Discourse (pp. 97-118). Amsterdam: Benjamins.

https://doi.org/10.1075/pbns.221.07war

Warneken, F., \& Tomasello, M. (2009). The Roots of Human Altruism. British Journal of Psychology, 100, 455-471. https://doi.org/10.1348/000712608X379061

Wotton, A. J. (1981). Two Request Forms of Four Year Olds. Journal of Pragmatics, 6, 511-523. https://doi.org/10.1016/0378-2166(81)90016-3

Yu, G. D., \& Wu, Y. X. (2018). Inviting in Mandarin: Anticipating the Likelihood of the Success of an Invitation. Journal of Pragmatics, 125, 130-148.

https://doi.org/10.1016/j.pragma.2017.06.013 


\section{Abbreviations}

$\mathrm{NOM}=$ nominalizer $(\mathrm{de})$

$\mathrm{N}=$ negator

$\mathrm{PRT}=$ particle

$\mathrm{C}=$ classifier

ASSOC $=$ associative $(-\mathrm{de})$

ASP $=$ aspectual marker

$\mathrm{BA}=$ ba-construction

$\mathrm{BE}=$ be (verb) (shi)

$\mathrm{NUM}=$ Number

$\mathrm{PFV}=$ perfective aspect marker

CRS $=$ currently relevant state $(-\mathrm{le})$

CSC $=$ complex stative construction (-de)

INT $=$ interjection

DUR = durative aspect (one kind of ASP) 